\title{
POSITIVE ACADEMIC SUPERVISION: A CASE STUDY IN A TOURISM UNDERGRADUATE COURSE AT A PUBLIC UNIVERSITY IN THE STATE OF PARANÁ, BRAZIL
}

\author{
Ana Cristina Rempel de Oliveira ${ }^{a}$ \\ Claudio Alexandre de Souza ${ }^{b}$ \\ Andreia Diedrich Gracianoc
}

\begin{abstract}
This report of experience describes took place in the academic context and aimed to study the relationship between an academic advisor and their student. The research problem emerged from the positive and negative experiences of two of the authors, during their timeas students under supervision at the university. In 2018, these authors had the opportunity, as advisors, to apply techniques to carry out positive supervision. The objective of this report was to present positive experiences of academic supervision for the production of a thesis for the undergraduate course of Tourism of a public university in the state of Paraná, Brazil. This study was carried out in 2018 , and involved the supervision of two students, with thirteen steps, as described in this report. The results of the supervision were two undergraduate theses that were approved and received praise, and two students who were satisfied with the process. As practical implications, we observed that when the advisor and student are bothclear as to the student's role as the protagonist of the process, the teaching-learning process generates results in terms of knowledge construction and application of this knowledge in the studied context. Thus, positive supervision can improve the student's professional and/or social context. In the cases studied here, the students and their advisors worked together from the start of development of the undergraduate thesis; and shared their empirical and scientific knowledge.
\end{abstract}

KEYWORDS: positive academic supervision, advisor, advisee, undergraduate thesis. 


\section{INTRODUCTION}

This work reports an experience that took place in the academic context and aims to study the relationship between advisor and student. This relationship is a complex one, as it involves people with different personalities, ages, and experiences. Being full of subjectivities, this relationship requires a clear demarcation of the rights and duties of each subject and their role inthe academic supervision process. But what does an advisor do?

The advisor's role should be that of an educator who shares his/her more mature experience with the advisee in a joint process of knowledge construction. Two parties interact in a dialogue process, respecting the autonomy and personality of each party. The advisor is neither a father, nor a mentor, nor a defense lawyer, nor an analyst; but neither is he/she an overseer, a colonel, or anything like that. The advisor is an educator establishing an educational relationship with the advisee, with all that it means in terms of scientific production (SEVERINO, 2006, p. 77-8).

Based on Severino's (2006) explanation, we can assume that the advisor shares his/her knowledge and experience with the student during the process of constructing scientific knowledge, so that the student, in turn, can mature and learn through the processes of acquiring and sharing knowledge. The aim of this report was to present positive experiences of academic supervision for the production of an undergraduate thesis carried out as a requirement of the undergraduate course in Tourism at a public university in the state of Paraná, Brazil.

The supervisory process can be understood as the actions that take place within the scope of the relationship between the advisor and the student or advisee, from the verbal contract between the parties through to delivery of the final version of the undergraduate thesis. It may be extended to monitoring the publication of the research results, the selection of a postgraduate program, or professional guidance, depending on the parties' interests.

This report was structured in four sections, besides this introduction. The sections are:Research problem and relevance, Methodology, Results, and Practical implications and conclusions

\section{RESEARCH PROBLEM AND RELE- VANCE:}

We addressed the research problem of the report based on the needs that emerged from the experience of two of the authors, who had at least five different advisors each during their academic education. In sharing these experiences between 2009 and 2018, these researchers identified positive and negative aspects of the supervision they had received, which did not always contribute to the students' performance in the development of research.

The invitation to act as advisor and co-advisor for two undergraduate theses in a Tourism undergraduate course at a public university in Paraná arose in 2018. The problem, at that time, was: How to promote a positivesupervision experience in the writing of undergraduate theses for a Tourism course at a public university in Paraná?

Why is a positive supervision experience so important? When reflecting on these questions, we should consider all fields of knowledge, not only tourism or other areas of applied social sciences, and the opportunity that an undergraduate thesis represents for the student, to build scientific knowledge that can contribute to society. Furthermore, the student may sometimes develop an interest in research, improve his/her skills, and increase his/her potential to make academic or practical contributions to their community or country. The advisor's role is to lead the student during this process.

But what are the chances of a student who had had a negative supervision experience while writing their undergraduate thesis wanting to continue developing and improving their research, by going on to take a master's program or doctorate degree, and who knows, developing some innovative solution for a country like Brazil, which is increasingly dependent on technology imports.

Positive supervision can influence not only an individual's life, but also an area of expertise, an economic sector, or even a country. If every academic advisor performed positive supervision, encouraging researchers 
who were happy in their processes of production of scientific knowledge in all fields of knowledge, people would see sciences, and the world of research, as pleasant and rewarding. This would result in more students taking an interest in research, more researchbeing carried out, more innovation, and better trained human resources, thus improving our society in the social and economic contexts.

\section{METHODOLOGY}

Two tourism undergraduate students from a public university in Paraná participated in this positive academic supervision experience for the production of an undergraduate thesis. This process started in 2018, when the students began their final year in the course and had to start thinking about their undergraduate thesis. At this point, they had to look for teachers who would act as advisors and co-advisors. The advisors saw the opportunity to put into practice the aspects necessary for positive advising. The main steps were as follows:

- Psychological contract: we initially defined the roles of the parties involved and the importance of meeting deadlines for production and correction of content, which resulted in an initial schedule. We established communication channels and operational questions about storage and sharing of research-related files. Then, we moved on to the next activity.

- Support for the free choice of topic: the student does not always have a clearly-defined research topic in mind when looking for an advisor, as was the case here. To start a positive supervision experience, the first step was to help the students identify a topic of interest that they could relate to and that they felt would be useful for them. For this, it was necessary to look at the students' personal and professional characteristics. Had the topics been imposed on the students by the advisors, the development of the research, which requires a lot of dedication, would probably have been torture for the students.

The advisor can suggest that the student writes down topics of interest and presents them in the next meeting, or sends them in a few days. These topics may be related to some professional activity that the student is already involved in. The student must choose the topic, so that he/she feels the research is his/her own and takes full responsibility for it.

- Research problem and delimitation of the research: a difficulty that many students have is having a "researchable" idea. They may have lots ofvery good ideas, but it is hard for them to extract a problem and an objective that will lend itself well to research. This difficulty may be due to a lack of practical experience, since this exercise is not often encouraged in the first years of undergraduate courses. Thus, when the students first arrived with their ideas, it was necessary to translate them into academic language.

Next, we had to think about the scale of this idea, and whether it would be possible to execute it within the time available. In this case, the answer is usually negative, but the advisors must reason with their students, and help them come to the right conclusion rather than concluding for them, even if they already know the answer. Clearly, intervention is necessary when students are unable to reach this conclusion by themselves.

In our experience, the advisors explained the research paths according to the problem and objective proposed by the students, as well as the type of research required, the timeframe, and the need for availability and dedication, checking that the students agreed and were comfortable with what was to come. In case of a negative answer, the advisors would have to adjust the problem and objective to the student's ability and availability. After all, proposing something the students could not do would be extremely frustrating for all parties.

Next, the problem and objective were adjusted to form an achievable reality for the students.

- Outlining the project: the university required a written paper in the form of an undergraduate thesis. Thus, once a problem and an objective of a performable research project had been validated by the students, it was time to outline the project. This consists in building a structure that shows how each part of the paper will be developed: - introduction, theoretical framework, methodology, data analysis, final considerations - and most importantly, what should go in each section, according to the study to be elabo- 
rated. The outline helped the students have a vision of the whole, and of the work required, which reduces anxiety in the advisor's perception, as anxiety is caused by a fear of the unknown.

Regarding the theoretical framework, the advisors suggested including only topics that were directly related to the study objective and that would be useful for discussing the results found during the development of the research. The advisors explained how and where the students should look for sources.

Regarding the theoretical framework, the advisors suggested including only topics that were directly related to the study objective and that would be useful for discussing the results found during the development of the research. The advisors explained how and where the students should look for sources.

- Academic writing: students usually have difficulty with academic writing. What is the best way to teach them? Encouraging practice, making constructive corrections, not underestimating what they have produced, and not using adjectives that devalue the student or his/her production. Advisors are supposed to suggest how to write or how to improve arguments, and not only indicate what is wrong, so that the student can improve it. If the student has difficulty with grammar, the text can be sent for professional proofreading. At this point, the focus should be on the research and not on the correct spelling. After all, there is already a lot of pressure on the student.

This difficulty arises from the lack of practice during the undergraduate course, so the advisor must be aware of students' understanding of how to improve their academic writing. the students must feel comfortable asking the advisor questions. However, if the advisor tells the student off for their mistakes, the production will lose quality and deadlines may be missed, as the stages of theoretical review and writing may take longer under these conditions.

Corrections and feedback should be given as quickly as possible, ideally within a week, so that the students do not lose their train of thought and pace. This also allows the student a a period to distance themselves from the text, regain a sense of critical awareness, and then return to the text and improve it.

- Preparation of a data collection instrument (where applicable): In the two experiences assessed for this report, the students had to elaborate data collection instruments - and psychography would not help. The elaboration of the collection instrument must come out of the theoretical review, based on the experience of other researchers, and must be adapted to the research context. The advisors helped the students consider the methods and period for the data collection, to avoid rework.

- Data collection: Advisors must teach best practice guidelines for data collection, depending on the research context.

- Data treatment and analysis: Many students have never treated or analyzed data before. This may, therefore, be a phase when students need more support from their advisors. In addition to this difficulty, the fact that it usually getting close to the end of the term by this time can put additional pressure on the students. In the case of the two students of this case study, the advisors subjectively verified the students' level of autonomy for this activity and identified their difficulty in analyzing the data. This process was thereforecompleted with the active participation of the advisors. The advisors needed to explain which technique would be used, the reason for selecting this technique, how the tools worked, and how to interpret the results. Without understanding this part of the process, the students would have had difficulty moving forward.

- Writing the data analysis: This stage also had with many doubts from the students. The main question was what to highlight. Therefore, according to each study (qualitative and quantitative), the advisors also had to give more support to the students in this stage, showing them how to share the results obtained, mainly with examples. At this point, there is no better way to learn than by doing and improving. Ideally, the advisor should correct part of the results section and return it to the student. Then the student can understand how it should be done and continue writing with the necessary adjustment. This process avoids frustrations and rework during writing.

- Writing the final remarks: By this stage, the students were more relaxed. They followed the topics as developed in the outline, while the advisors made corrections and adjustments.

- Final review: The advisor must give a critical review concerning whether the research has adhered to the 
initially proposed problem and objective, and analyze whether any general adjustments are needed, to ensure the success of the thesis defense.

- Preparing for the thesis defense: As it was the students' first thesis defense, they were anxious. In this case, knowing more about how it works, or watching other thesis defenses, can help reduce that feeling. Also, structuring the necessary content helped the students prepare their presentations so that they wouldn'tforget anything. Rehearsing the presentation with the students, checking that all the allotted time is filled, and checking posture and communication also helps students feel more self-confident. Thinking about the possible questions that might arise, and the possible answers, also helps in the student's preparation.

- Adjustments and corrections: the thesis defense committee usually suggests some adjustments and corrections. After the defense, the advisors should meet with the student to discuss any changes will be made to the final version of the work.

In all stages of the research - highlighted above and summarized in Appendix A -, the advisors valued mutual respect, trust, and consideration in all dialogues. Also, the positive communication of mistakes helped a lot in building the research, as the advisors not only point out the errors, but also suggested how to fix them. Reassuring the students was essential since the undergraduate thesis is normally a terrifying topic for undergraduate students.

\section{RESULTS}

The positive supervision experience took place during the academic year of 2018, with two undergraduate tourism students at a public university in Paraná, Brazil. We have described all thirteen stages of the supervision that were the object of this experience report: from the definition of the topic, problem, and objective through to the final stages of preparation for the thesis defense, and final adjustments.

The results achieved were two undergraduate theses that were approved and praised, and two happy, satisfied students, fulfilled with their research experience.

Thus, we validated the techniques needed for positive academic supervision. But how can we be so sure? In addition to the students' satisfaction, one of them improved her research, entered a master's program, and is satisfied with the idea of producing research and publishing papers. She has also received an invitation from other professors to participate in research projects and is a co-author in this experience. The other student entered another undergraduate course in a field related to that of her undergraduate thesis, and is still keen to gain more knowledge applicable to her professional activity.

This result is related to the strong value attributed to the students' scientific, empirical, and philosophical knowledge from the beginning of the process, and to the fact that they were free to choose study subjects connected with their lives and community. Therefore, valuing the students' knowledge and environment means allowing them to develop solutions for their community and companies in their field of activity, through the results obtained in the research. This may contribute to the economic and environmental sustainability of these activities by improving processes or applied technologies, or reducing waste, for example. It may also lead to the creation of new businesses.

Replicating this experience is low in cost, as the main resources are already available at universities - advisors and advisees. However, it is necessary to raise awareness, among staff and professors, so that positive academic supervision can become part of the academic culture of institutions.

Although the financial investment is low and it is easily replicable, this experiment would not be possible without the autonomy of the advising professor - which was the case in this report of experience, and without the student's understanding of their role. But positive results cannot always be guaranteed when replicating the steps mentioned, as there may be other variables involved, that were not observed in this experience.

\section{PRACTICAL IMPLICATIONS AND CON- CLUSIONS}

This report of experience presents information collected from two supervision experiences with two tourism undergraduate students at a public university in Paraná, 
Brazil. Our aim was to explain, explore or describe phenomena; therefore, this report is a case study (YIN, 2003).

On the one hand, this experience does not seem to anything innovative in general, as universities and undergraduate theses have existed for many decades. On the other hand, when thinking about the applicability and quality of some studies resulting from the tourism undergraduate course, the authors concluded it was possible to bring an innovative approach to this traditional academic practice, and one with the potential to improve the tourism industry.

For instance, as a result of this experience, one of the advisees is now furthering her research through a master's degree program. The improvements she identified have led researchers to create a startup to assist wedding management companies. The results of the undergraduate theses revealed potential opportunities for business improvement in partner companies.

If disseminated, this report of experience can benefit many undergraduate courses in Brazil that require the development of an undergraduate thesis. Students may be effectively guided to understand how scientific research can contribute to society, and become professionals and citizens aware of their reality and how to improve it.

Certainly, this experience can be applied in tourism courses in Brazil at all levels, from technician to doctoral programs. A process of continuous assessment of teaching activities can be built based on scientific, social, and professional indicators. This assessment has the potential to help the industry innovate, by training innovative students, which has not always been the case.

This experience can promote discussion and reflection among teachers, who must acknowledge their responsibility to lead students through a process of producing scientific knowledge that can contribute to their areas of knowledge, the community, and the country as a whole.

\section{REFERENCES} Publications, Inc ISBN 0, v. 761, n. 92553, p. 8, 2003.
SEVERINO, Antônio Joaquim. Pós-graduação e pesquisa: o processo de produção e de sistematização do conhecimento no campo educacional. In: BIANCHETTI, Lucídio; MACHADO, Ana Maria Netto (Org.). A bússola do escrever: desafios e estratégias na orientação e escrita de teses e dissertações. 2. ed. Florianópolis, Ed. da UFSC; São Paulo: Cortez, 2006. p. 67-87. 


\section{POSITIVE ACADEMIC ADVISING}

\section{Psychological contract \\ To deline the roles of paries and the importance of meeting deadines for production and content correction. To establish communication channels and operational questions about storage and sharing of research-related flies.}

\section{Academic writing}

To encourage the practice of writing and make constructive corrections, not underestimating what was produced, and not using adjectives that devalue the student or his/ner production. To suggest how towrite or how to improve arguments.

9. Writing data analysis

3 To provide examples on how to report the results found.$$
\text { (n) }
$$

\section{Support for the free choice of topic}

2 To help students identify a topic they like, that they are related to, and that made them feel useful. To do so, $\mathrm{k}$ is necessary to look at the students integrally, as peop and protessionas.

6. Preparation of a data
collection instrument
(when applicable)

$\checkmark$ To star trom the theoretical review, from ather researchers' experience, and to adapt the findings to the research context
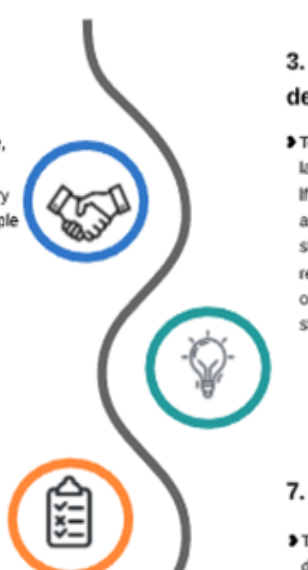

3. Problem and research delimitation

To translate the topic proposed into academic language. To reflect upon the size of this bea and if $\mathrm{h}$ is possible to execute $\mathrm{k}$ within the time avaliable. To contribute with reasoning and help students reach the best conclusion. To expose the research parths according to the problem and objective and aclust the pa:hs according to the students' conditions and avaliability.
7. Data collection

- To provide the best practice guidelines for data collection, which depend on the research context

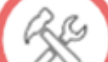

\section{Outlining the project}

To structure each part of the paper incroduction, theorebical framework, methodology, data analysis, final considerations - and most importanty what "tilly" each of section.

\section{Data treatment and} analysis

2To verity subjectively the students' level of autonomy for this activily. In case of difficully, to explain which technique will be used, the reason for selecting this technique, how the tools work, and how to interpret the results.

\section{Preparing for the} thesis defense

To structure the necessary content. in addition, to rehearse the presentation with the advisees and to checking posture, communication, and it the Ume allowed is being fultuled.

13. Adjustments and corrections

To ollscuss which changes will be made to

the final version of the work.

adherence of the problem and objective what was produced and anabze if any advisors make corrections and acjustments. 